\title{
La dimensió territorial de la innovació social: una mostra de pràctiques de lideratge col-lectiu a Nou Barris Nord i Sants*
}

\author{
Santiago Eizaguirre \\ Universitat de Barcelona. Departament de Sociologia \\ santieizaguirre@ub.edu

\section{Marc Parés} \\ Universitat Autònoma de Barcelona. Departament de Geografia \\ marc.pares@uab.cat
}

\section{Resum}

Aquest article compara quatre iniciatives socialment innovadores als territoris de Sants i Nou Barris Nord (Barcelona). La principal tesi que es desenvolupa és que els estudis d'innovació social, a part d'atendre la dimensió territorial d'aquestes iniciatives, haurien de considerar també les dinàmiques de lideratge col-lectiu que s'hi desenvolupen. En aquest sentit, s'identifiquen tres pràctiques de lideratge que resulten especialment rellevants per entendre els impactes de la innovació social en termes d'eficàcia i escalabilitat: la reformulació del discurs, la construcció de ponts entre diferents grups i actors socials i l'alliberament d'energies humanes. Concloem que el context històrico-geogràfic té un paper fonamental a l'hora d'entendre tant el sorgiment com l'impacte d'aquestes iniciatives. Tanmateix, l'agència resulta igualment important, especialment quan les condicions contextuals són adverses. La dialèctica entre el context i l'agència, així com la construcció de capacitats comunitàries als barris, apareixen com a factors clau per al foment d'una innovació social realment transformadora.

Paraules clau: innovació social; lideratge col-lectiu; transformació social; escalabilitat; crisi

* Aquest treball ha estat possible gràcies al finançament de les Accions Marie Curie del 7è Programa Marc de la Unió Europea sota el Grant Agreement Núm: 625070-FP7-PEOPLE-2013-IOF. Volem agrair també la contribució en aquesta recerca dels professors Joan Subirats (UAB) i Sonia Ospina (NYU). 
Resumen. La dimensión territorial de la innovación social: una muestra de prácticas de liderazgo colectivo en Nou Barris Nord y Sants

Este artículo compara cuatro iniciativas socialmente innovadoras en los territorios de Sants y Nou Barris Nord (Barcelona). La principal tesis que se desarrolla es que los estudios de innovación social, aparte de atender a la dimensión territorial de estas iniciativas, deberían considerar también las dinámicas de liderazgo colectivo que se desarrollan. En este sentido, se identifican tres prácticas de liderazgo que resultan especialmente relevantes para entender los impactos de la innovación social en términos de eficacia y escalabilidad: la reformulación del discurso, la construcción de puentes entre diferentes grupos y actores sociales y la liberación de energías humanas. Concluimos que el contexto histórico-geográfico desempeña un papel fundamental a la hora de entender tanto el surgimiento como el impacto de estas iniciativas. Sin embargo, la agencia resulta igualmente importante, especialmente cuando las condiciones contextuales son adversas. La dialéctica entre el contexto y la agencia, así como la construcción de capacidades comunitarias en los barrios, aparecen como factores clave para el fomento de una innovación social realmente transformadora.

Palabras clave: innovación social; liderazgo colectivo; transformación social; escalabilidad; crisis

Résumé. La dimension territoriale de l'innovation sociale : un échantillon de pratiques de leadership collectif dans les quartiers de Nou Barris Nord et de Sants

Cet article compare quatre initiatives socialement innovantes dans les territoires du Nou Barris Nord et de Sants (Barcelone). La thèse principale est que les études d'innovation sociale, en plus de traiter la dimension territoriale de ces initiatives, devraient également considérer les dynamiques de leadership collectif qui s'y développent. En ce sens, nous avons identifié trois pratiques de leadership qui sont particulièrement pertinentes pour comprendre les impacts de l'innovation sociale en termes d'efficacité et d'évolutivité : la reformulation du discours, la construction de ponts entre les différents groupes et les parties prenantes, et la libération de l'énergie humaine. Nous concluons que le contexte historique et géographique joue un rôle clé dans la compréhension à la fois de l'apparition et de l'impact de ces initiatives. Cependant, l'agence est tout aussi importante, en particulier lorsque les conditions contextuelles sont défavorables. La dialectique entre le contexte et l'agence, ainsi que le renforcement des capacités communautaires dans les quartiers, apparaissent comme des facteurs clés dans la promotion d'une innovation sociale véritablement transformatrice.

Mots-clés: innovation sociale; leadership collectif; transformation sociale; évolutivité; crise

\section{Abstract. The territorial dimension of social innovation: A sample of collective leadership practices in Nou Barris Nord and Sants}

This article compares four socially innovative initiatives in the territories of North Nou Barris and Sants (Barcelona). The main thesis is that social innovation studies, apart from addressing the territorial dimension of these initiatives, should also take into account the development of collective leadership dynamics. In this regard, we identify three leadership practices that are particularly relevant to understanding the impacts of social innovation in terms of efficiency and scalability: the reframing of discourse, the bridging of differences and the unleashing of human energies. We conclude that the historical and geographical context plays a key role in understanding both the rise and the impact of these initiatives. 
However, agency is equally important, especially when contextual conditions are adverse. The dialectic between context and the agency, as well as community capacity building at neighbourhood level are found to be key factors in promoting a truly transformative social innovation.

Keywords: social innovation; collective leadership; social transformation; scalability; crisis

\section{Sumari}

1. Introducció: territori, innovació social i lideratge

2. Matriu analítica i consideracions metodològiques

3. Sants: pràctiques contrahegemòniques en un barri molt polititzat
4. Nou Barris Nord: solidaritat i resistència per fer front als efectes de la crisi

5. Síntesi analítica

Referències bibliogràfiques

\section{Introducció: territori, innovació social i lideratge}

És freqüent en els estudis urbans que la innovació social sigui conceptualitzada com un mecanisme per millorar el desenvolupament territorial de barris desfavorits (MacCallum et al., 2009; Moulaert et al., 2010). Aquesta aproximació subratlla la importància del context històric i geogràfic a l'hora d'entendre com emergeixen les iniciatives socialment innovadores i com aquestes poden promoure processos de canvi social. Per contra, malgrat que la literatura sobre innovació social ha estat molt fructífera durant la darrera dècada (Moulaert et al. 2013), s'ha parat poca atenció a les dinàmiques d'agència que podrien contribuir també a explicar no només el fet que la innovació social sorgeixi en uns llocs i no en uns altres, sinó també la seva capacitat d'impacte. En aquest sentit, l'estudi del lideratge en els processos d'innovació social —l'observació de l'agència que els produeix - ha tendit a ser poc present en les publicacions especialitzades (Parés et al., 2017)

Aquest article utilitza les teories del lideratge per introduir l'agència en la perspectiva territorial sobre les dinàmiques d'innovació social. Analitzant conjuntament els "condicionants territorials de barri" $\mathrm{i}$ les "pràctiques de lideratge col-lectiu» s'aspira a comprendre millor com les comunitats s'enfronten als efectes de la recessió econòmica mitjançant iniciatives socialment innovadores. Més concretament, interessen els impactes que aquestes iniciatives busquen i provoquen, definint aquests impactes en termes d'eficàcia i escalabilitat.

Per tal d'assolir aquest objectiu, s'ha dut a terme un estudi comparatiu de quatre iniciatives socialment innovadores incrustades en dos territoris barcelonins que, com veurem, han respost a la crisi econòmico-financera de 2008 de forma ben diferent: Sants i Nou Barris Nord. Justament a través de la metodologia de l'estudi comparat de casos territorialment incrustats (Yin, 2003) 
s'aconsegueix abordar i relacionar aquestes dues dimensions analítiques: el context territorial i les pràctiques de lideratge col-lectiu.

En l'apartat següent s'explica la matriu analítica utilitzada, es defineixen les principals variables que han guiat l'anàlisi i es detalla la metodologia emprada. Tot seguit es desenvolupen els estudis de cas contextualitzant-los en els seus respectius territoris. Finalment, es conclou posant en relació les dimensions analítiques a través de la comparació entre els casos i formulant algunes recomanacions per al foment d'una innovació social transformadora.

\section{Matriu analítica i consideracions metodològiques}

Aquest article presenta els resultats del treball de camp dut a terme a Barcelona en el marc del projecte SOCRISIS. ${ }^{1}$ Es pot veure a continuació com s'han entès les principals variables d'aquest estudi per tal de, tot seguit, desenvolupar breument la metodologia utilitzada.

\subsection{Els impactes de la innovació social transformadora: eficàcia i escalabilitat}

Un dels grans debats entorn de la innovació social fa referència al seu caràcter transformador. El projecte TRANSIT, ${ }^{2}$ per exemple, entén que la innovació social és transformadora quan desafia, altera o substitueix les estructures i les institucions dominants. De forma similar, autors com Moulaert et al. (2013) o Oosterlynck et al. (2013) destaquen que el tret diferencial de la innovació social transformadora és la seva capacitat per produir canvis en les relacions socials i de poder. Bevent d'aquesta literatura, que entén la innovació social com una cosa disruptiva, l'estudi que aquí es presenta ha volgut operacionalitzar aquesta capacitat transformadora a través de dues dimensions: l'eficàcia (en quina mesura una iniciativa socialment innovadora assoleix objectius transformadors d'acord amb aquestes definicions) i l'escalabilitat (en quina mesura l'efecte transformador supera els límits de la mateixa iniciativa).

Així, s'entén l'eficàcia com la capacitat d'una iniciativa social per assolir la transformació desitjada en relació amb tres objectius: $a$ ) resoldre el problema social al qual mira d'oferir resposta; $b$ ) apoderar la ciutadania; i $c$ ) produir canvis en les relacions socials i de poder. En aquest sentit, com s'ha posat en relleu en recerques prèvies, les relacions de governança entre les administracions públiques i les iniciatives d'innovació social tenen un paper molt important (Parés et al., 2012; Eizaguirre et al., 2012; Pradel et al., 2013).

D'altra banda, fent referència a l'escalabilitat es vol caracteritzar la capacitat de les iniciatives per expandir-se i créixer, així com la possibilitat de ser replicades en altres contextos. L'escalabilitat, doncs, té un doble sentit: la capacitat d'ampliar el radi d'acció o el nombre de persones beneficiaries o implicades

1. Social innovation against the crisis: how leadership practices and civic capacity improve neighbourhood development. <www.socrisis.net>.

2. Transformative Social Innovation Theory: <www.transitsocialinnovation.eu>. 
(scaling out) i la capacitat d'una iniciativa per ser replicada en altres contextos geogràfics i escales governamentals (scaling up).

\subsection{Les pràctiques de lideratge col-lectiu}

De manera paral.lela a la popularització de les estratègies d'innovació social, conceptes com lideratge col-lectiu, distribuït, col-laboratiu o compartit estan guanyant cada cop més atenció tant en la literatura acadèmica (Uhl-Bien i Ospina, 2012) com des d'una perspectiva aplicada (Heifetz et al., 2009). Anant més enllà de l'atenció als líders formals i la seva influència en els seus seguidors, aquestes noves aproximacions a l'estudi del lideratge evolucionen cap a una perspectiva més crítica que para atenció als processos relacionals vinculats amb la constitució d'un lideratge compartit (Ospina i El Hadidy, 2013; Ospina, 2006). Això implica una comprensió de l'agència en un sentit col-lectiu com un aspecte clau dels processos d'innovació social.

Basant-nos en la literatura específica que s'ha desenvolupat sobre aquesta qüestió en l'entorn acadèmic de la NYU Robert F. Wagner Graduate School of Public Service (Ospina et al., 2012), hem centrat l'anàlisi en tres tipus de pràctiques de lideratge: $a$ ) reformular el discurs (reframing discourse), b) construir ponts entre diferents actors (bridging difference) i $c$ ) alliberar les energies humanes (unleashing human energies). "Reformular el discurs» es refereix a aquelles pràctiques de lideratge que transformen les línies d'anàlisi amb nous llenguatges i proposant altres maneres de conceptualitzar les problemàtiques socials. Es tracta d'aquelles pràctiques de redefinició de les problemàtiques socials amb què tracten les organitzacions o iniciatives en qüestió que incideixen amb perspectives més congruents amb la seva visió del futur. "Construir ponts entre diferents actors» té a veure amb aquelles pràctiques inclusives que s'orienten a crear les condicions per relacionar actors o grups socials diversos, salvant les diferències, teixint aliances per cohesionar els participants d'una iniciativa o col-laborant amb altres organitzacions. Finalment, «alliberar les energies humanes» de les persones que formen part d'una iniciativa fa referència a les pràctiques de lideratge que promouen l'apoderament igualitari de persones en situacions vulnerables dotant-les de capacitats humanes i organitzatives.

\subsection{Selecció dels casos i recol-lecció de dades}

Els dos territoris barcelonins seleccionats per a la recerca han estat colpejats pels efectes socioeconòmics de la crisi econòmico-financera de 2008, tal com es pot observar en les dades de renda familiar disponible (taula 1). Malgrat això, Sants ${ }^{3}$ és un barri amb un teixit social i associatiu molt actiu que ha resistit millor la crisi que Nou Barris Nord, ${ }^{4}$ una àrea molt més vulnerable i amb un capital social molt fragmentat.

3. L'àrea d'estudi a Sants inclou els barris de Sants i la Bordeta.

4. Nou Barris Nord engloba els barris de Torre Baró, Ciutat Meridiana i Vallbona. 
Taula 1. Estudis de casos

\begin{tabular}{|c|c|c|c|c|c|c|}
\hline & \multicolumn{3}{|c|}{ Sants } & \multicolumn{3}{|c|}{ Nou Barris Nord } \\
\hline & & 2008 & 2014 & & 2008 & 2014 \\
\hline Població & & 59.881 & 59.550 & & 14.585 & 14.062 \\
\hline Superfície $\left(\mathrm{km}^{2}\right)$ & & 1,7 & 1,7 & & 2,8 & 2,8 \\
\hline Densitat (hab/km²) & & 35.224 & 35.029 & & 5.209 & 5.022 \\
\hline \multirow{3}{*}{$\begin{array}{l}\text { Índex de renda familiar } \\
\text { disponible (Barcelona }=100)\end{array}$} & Sants & 87,1 & 85,8 & Torre Baró & 62,1 & 45,6 \\
\hline & La Bordeta & 80,8 & 76,0 & Ciutat Meridiana & 58,8 & 39,2 \\
\hline & & & & Vallbona & 59,6 & 39,9 \\
\hline
\end{tabular}

Font: Ajuntament de Barcelona.

La selecció de les iniciatives estudiades en cada territori s'ha fet buscant experiències que oferissin respostes a la crisi que poguessin encaixar dins la definició més acceptada en l'entorn acadèmic del que és la innovació social transformadora. S'ha considerat en cadascun dels dos territoris una iniciativa apareguda en el context de crisi, amb un origen posterior a 2008 (la PAH a Sants i $50 \times 20$ a Nou Barris Nord) i una iniciativa que provingués d'una organització ja existent o de lluites promogudes abans de l'esclat de la crisi (Recuperem Can Batlló a Sants i el Centre Cruilla a Nou Barris Nord).

La principal tècnica de recollida de dades ha estat l'entrevista amb informadors privilegiats. S'han fet a cadascun dels territoris quinze entrevistes entre novembre de 2015 i gener de 2016. Les persones entrevistades han estat escollides en la majoria dels casos perquè eren representants de les entitats objecte d'estudi, tot i que també s'han fet entrevistes a responsables tècnics del treball sociocomunitari promogut per les administracions públiques al territori, com també a membres actius del moviment veïnal no necessàriament vinculats de manera directa a les entitats analitzades. Les entrevistes s'han fet en dues onades (seguint dos tipus de guions d'entrevista): una primera onada orientada a la caracterització dels efectes de la crisi al territori, parant atenció a la resiliència i la capacitat cívica del veïnat i el teixit associatiu; i una segona onada parant atenció a l'organització específica de les iniciatives d'innovació social seleccionades i fent èmfasi en les pràctiques de lideratge desenvolupades per aquestes. A part de les fonts de dades secundàries i la documentació publicada sobre els casos seleccionats, s'han utilitzat també dades recol-lectades en projectes anteriors, com és el cas dels projectes Barris i Crisi ${ }^{5}$ i POLURB. ${ }^{6}$

\section{Sants: pràctiques contrahegemòniques en un barri molt polititzat}

Malgrat que Sants és un barri tradicionalment de classe treballadora, no ha estat colpejat de manera extrema per la recessió. No obstant això, a diferència

5. <www.barrisicrisi.wordpress.com>.

6. Els resultats del projecte POLURB han donat lloc a diverses publicacions, entre les quals destaquen les següents: Subirats i Martí-Costa (2014 i 2015); Subirats i García-Bernados (2015). 
d'altres territoris de la ciutat, el barri de Sants és avui molt més pobre ara que abans de l'inici de la crisi. L'atur ha crescut significativament, nombrosos negocis petits han tancat i els desnonaments i les execucions hipotecàries s'han disparat.

Amb el seu caràcter de petit poble dins de la ciutat, Sants ha retingut un alt sentit de pertinença entre els seus habitants, que es manifesta en el fort caràcter de les seves organitzacions socials. El barri ha acumulat l'experiència de nombroses lluites històriques i un nivell significativament alt d'activisme polític. Això fa que en l'actualitat puguem parlar de diverses generacions d'activistes compartint mobilitzacions i lluites al territori. Les fites assolides per aquestes lluites, com també l'aprenentatge social que se'n deriva, es manifesten en l'existència d'una rica mescla d'organitzacions socials que no només coexisteixen sinó que també col-laboren duent a terme campanyes i accions per al desenvolupament comunitari.

La innovació social a Sants no és una cosa nova. No és una resposta a la situació postrecessió; al contrari, es tracta del resultat d'una tradició d'acció col-lectiva de base que té unes arrels històriques profundes, molt diverses i polititzades. En aquest sentit, a Sants hi trobem el principal nucli del cooperativisme democràtic català contemporani, que esdevé un referent del moviment autogestionari i on la cultura autoorganitzativa per part de les classes populars és present al carrer. Això s'explica per una tradició d'acció autònoma que floreix a la societat civil local contraposant-se a les dinàmiques de gestió i organització derivades de les lògiques de l'estat i del mercat. Recentment, d'altra banda, han sorgit noves iniciatives que, mesclant velles i noves mobilitzacions de base, han tret profit de tot el coneixement acumulat al barri. En aquest sentit, Sants alberga una classe de gent econòmicament precària però culturalment molt formada. Persones joves, amb estudis superiors, polititzades i amb idees sovint transgressores.

\subsection{La plataforma Recuperem Can Batlló}

L'experiència de Recuperem Can Batlló recull els anhels de transformació sociocomunitària de part del teixit associatiu i els moviments socials amb presència a Sants. Consta d'un projecte d'ambició integral, que s'aproxima a l'abordatge transversal de diferents camps existencials (participació, cultura, habitatge, treball, desenvolupament econòmic, educació) des d'una perspectiva postcapitalista, compromesa amb el cooperativisme democràtic i l'autogestió de les classes populars.

Entroncant amb la tradició ateneista, enciclopèdica i llibertària del barri, la plataforma Recuperem Can Batlló ambiciona la promoció de diferents projectes complementaris que vehiculin una recuperació socialment transformadora de l'immens conjunt fabril de Can Batlló (LaCol, 2014). Entre aquests projectes, en l'actualitat, a part de la dinamització d'un espai de relació sociocomunitària i participació ciutadana com és l'anomenat Bloc Onze, s'està treballant en la construcció d'una cooperativa d'habitatges en règim de cessió 
d'ús (La Borda), en la promoció — amb la col-laboració de les administracions públiques - d'una agència de desenvolupament local amb perspectiva de ciutat orientada al foment de l'ocupació i l'emprenedoria en l'àmbit de l'economia social, cooperativa i solidària (COOPOLIS), i també en la creació d'una escola inspirada en la pedagogia lliure (Escola Arcàdia). Aquests projectes treballen de manera integrada, però amb l'autonomia necessària per establir diferents graus de col-laboració i compromís amb les administracions públiques.

Partint de la forta cultura democràtica d'autoorganització social i d'autonomia autogestionària que té gran part de la ciutadania activa del barri, l'organització de la plataforma Recuperem Can Batlló es basa en la presa de decisions de tipus assembleari entre les persones i entitats diverses que formen part de la iniciativa. El treball s'organitza a partir de nombroses comissions que articulen la cooperació de més de quatre-cents veïns i veïnes.

El lideratge dins d'aquesta iniciativa es caracteritza per un tipus de relacions que tendeixen al treball en xarxa i en les quals és molt present la rica cultura associativa del barri de Sants. L'equilibri entre la col-lectivitat i les personalitats dominants tendeix a resoldre's en favor de la col-lectivitat i, més concretament, a través de l'assemblea.

El principal impacte discursiu d'aquesta experiència, allò que es pot caracteritzar com a reformulació del discurs, es troba en la redefinició narrativa sobre el que és públic i pertany a la comunitat. La pràctica de l'autogestió i l'autoorganització del Bloc Onze, el desenvolupament dels projectes de futur que té la iniciativa, així com la complexitat de les relacions de la plataforma amb l'Administració pública posen l'èmfasi a reconèixer que allò públic va més enllà de la titularitat i les pràctiques de gestió promogudes des de les administracions. Des d'aquesta perspectiva, com destaquen Ojeda i Urbano (2015) referint-se a altres experiències similars que s'estan duent a terme a la ciutat, públic és el que és defensat per la comunitat, i no només allò que és promogut, gestionat o finançant per l'Administració.

L'observació de la manera com Recuperem Can Batlló incideix a construir ponts entre grups socials, entitats del barri i persones amb diferents històries i referents culturals és també important a l'hora de valorar l'impacte socialment transformador de la iniciativa. Enfortint el treball en xarxa i promovent formes de relació horitzontals entre associacions de diferents tipus, la plataforma no només arriba a un públic més ampli sinó que també incideix a promoure un teixit sociocomunitari apoderat i capaç de mobilitzar recursos de diferents tipus.

L'efecte d'apoderament de l'experiència en el teixit associatiu, dotant-lo de capacitat propositiva i potenciant la seva creativitat social, és segurament un dels atractius que ha captat l'atenció d'iniciatives similars. A més, des de la plataforma Recuperem Can Batlló s'ha fet un important esforç per difondre l'experiència mitjançant l'edició de documents historiogràfics de reflexió crítica, com llibres o audiovisuals. Malgrat que Can Batlló inspira moviments de recuperació d'espais obsolets en molts altres territoris, la transferibilitat de la iniciativa està condicionada pel fet que el projecte de recuperació de Can 
Batlló és d'una problemàtica, sobretot el conjunt fabril, d'unes dimensions gegantines difícilment repetibles.

\subsection{La Plataforma d'Afectats per la Hipoteca}

L'experiència de la Plataforma d'Afectats per la Hipoteca (PAH) de Barcelona és una iniciativa que té una escala d'acció que va més enllà del barri i s'enfoca a actuar a tota la ciutat, i més enllà d'aquesta, per incidir en les escales legislatives estatal i autonòmica. La PAH-Barcelona té la seu al barri de Sants des de l'any 2014, però anteriorment havia estat ubicada en altres barris de la ciutat (Ciutat Vella i el Clot). No es pot afirmar que sigui una entitat que s'identifica com a hereva dels trets característics del barri de Sants.

L'entitat té un àmbit d'acció centrat en l'autoorganització del col-lectiu afectat per la crisi de l'habitatge generada arran de l'esclat de la bombolla immobiliària. Les activitats que desenvolupa combinen les formes més tradicionals d'acció col-lectiva amb noves formes de política contenciosa basades en la confrontació entre moviments socials i administracions públiques (Romanos, 2014). Es pot resumir la seva acció en tres campanyes principals: a) Stop Desnonaments, orientada a promoure la mobilització col-lectiva i la desobediència activa per a l'aturada de les execucions hipotecàries; $b$ ) la campanya per la Iniciativa Legislativa Popular per a la dació en pagament, orientada a promoure el reconeixement jurídic de la dació en pagament i c) l'obra social de la PAH, una campanya per dotar de resposta habitacional i organitzativa les persones afectades per processos de desnonament.

El tipus d'organització amb el qual s'identifica la PAH és el d'un moviment social de caire horitzontal i assembleari (Mir Garcia et al., 2013) que té el treball voluntari com a principal font de recursos. En el cas de la PAH-Barcelona, a part de la participació i el treball de persones afectades per situacions d'impagaments d'hipoteques o lloguers, cal destacar la participació clau d'activistes pel dret a l'habitatge que adquireixen tasques de coordinació, representació i consultoria. Aquestes activitats són remunerades a través de l'Observatori dels Drets Econòmics i Socials de Catalunya (DESC) i sobre la base d'un conveni establert amb l'Ajuntament de Barcelona. Les activitats de la PAH-Barcelona, per tant, també inclouen tasques de representació consultiva al voltant de les polítiques públiques a escala municipal, regional i autonòmica. Això diferencia el perfil dels activistes que desenvolupen aquest tipus de pràctiques ${ }^{7}$ del perfil d'aquells activistes que s'identifiquen comunament amb l'aturada de desnonaments, les campanyes de denúncia o l'articulació de l'obra social de la PAH i que es tracta, en la majoria de casos, de persones afectades per la problemàtica. En aquest sentit, la construcció de ponts entre activistes pel dret a l'habitatge i afectats pels desnonaments és un punt clau per entendre l'impacte i l'escalabilitat assolida per aquesta iniciativa.

7. Durant l'any 2015 hi havia tres persones contractades a mitja jornada en el cas de la PAH-Barcelona que combinaven la militància a l'entitat amb el treball com a tècnics de l'Observatori DESC en projectes europeus de defensa del dret a l'habitatge. 
Encara que el nombre de persones que exerceixen tasques vinculades a la interlocució política i a la governança organitzativa de la plataforma és molt petit, les eleccions municipals de 2015 han marcat un canvi recent de tendència en el funcionament de la PAH. Durant el període que culmina amb el registre de la proposta d'Iniciativa Legislativa Popular per a la dació en pagament (2014), la influència de la $\mathrm{PAH}$ en l'esfera pública es pot caracteritzar com a intensa, de pressió i confrontació respecte dels postulats oficials a escala governamental. El pas d'Ada Colau de portaveu de la plataforma a Barcelona a alcaldessa de la ciutat, com també l'èxit electoral de les anomenades «candidatures del canvi» es poden relacionar amb un canvi de tendència en la dinàmica reivindicativa de la plataforma. En aquest context, l'acció de la plataforma passa a focalitzar-se en tasques propositives i de consultoria respecte de les polítiques socials d'habitatge.

És important assenyalar que, a part de projectar clarament una voluntat d'incidència política, la iniciativa ha donat molta importància a l'apoderament de les persones afectades per la crisi de l'habitatge i a la superació de la culpabilització i del victimisme, que les assenyalava com a culpables de la situació que patien. Aquesta superació ha estat vinculada a la manera com l'entitat ha treballat al voltant de l'apoderament col-lectiu a través de la capacitació (escola de la $\mathrm{PAH}$ ) i la creació de vincles entre persones amb una situació de vulnerabilitat socioeconòmica similar.

\section{Nou Barris Nord: solidaritat i resistència per fer front als efectes de la crisi}

Nou Barris Nord és un territori periferic que té un dels índexs de vulnerabilitat més alts de tot Barcelona. Ha estat sempre una zona urbana desfavorida que ha patit una estigmatització social i econòmica molt severa, així com una desatenció pública endèmica que es remunta al moment de la seva creació informal durant els anys seixanta del segle XX. En aquesta línia, la bombolla immobiliària de la primera dècada del segle XXI va multiplicar la segregació urbana i va promoure una dinàmica de substitució demogràfica molt intensa. El territori va esdevenir un laboratori abonat per a l'especulació immobiliària associada a la firma d'hipoteques creuades (Palomera, 2014) i va concentrar la població nouvinguda més pobra. El teixit social de Nou Barris Nord va patir les conseqüències d'aquesta substitució poblacional i es va debilitar i fragmentar (Blanco i Gomà, 2016).

En aquest context, l'emergència de respostes socialment innovadores no és facil. Quan les iniciatives floreixen, es troben condicionades per un context socioeconòmic molt deprimit que condiciona el potencial del seu impacte social. Sovint es tracta d'iniciatives clarament pragmàtiques que cerquen atendre la solució de problemes concrets relacionats amb necessitats socials bàsiques. Tendeixen a utilitzar aproximacions vinculades al desenvolupament comunitari que clamen a favor del desplegament de polítiques públiques i s'orienten a la reivindicació d'una forta inversió integral que compensi el greuge històric patit per aquests barris. 
Sense entrar en contradicció amb l'observació anterior, Nou Barris Nord té una important història de lluites veïnals i de mobilització col-lectiva per l'aprovisionament de serveis i recursos. En consonància amb aquests antecedents, veïns, associacions de veïns, parròquies $\mathrm{i}$ altres organitzacions han respost a través de la solidaritat i la resistència als efectes de la recessió.

El perfil de les persones que lideren les iniciatives d'innovació social al territori de Nou Barris Nord es podria sintetitzar amb dos grups. D'una banda, podem trobar veïns de mitjana edat o edat avançada que respondrien a les característiques pròpies de membres del moviment veïnal. Es tracta de persones que històricament han participat en els processos de mobilització i reivindicació veïnal. D'altra banda, trobem un segon grup de persones que, en alguns casos, comparteixen la característica d'estar vinculades amb el moviment veïnal com les anteriors, però que sobretot es caracteritzen perquè són professionals de l'acció social que treballen en àmbits com l'educació en el lleure, el treball social o l'educació comunitària.

\subsection{El Centre Cruïlla}

El Centre Cruilla s'orienta específicament al tractament de la inserció sociolaboral del col-lectiu juvenil i treballa principalment amb nois d'entre 16 i 25 anys. A part de la provisió de serveis formatius i sociocomunitaris associats amb l'apoderament d'aquest col-lectiu, el centre té un paper rellevant com a promotor i referent del desenvolupament comunitari de l'entorn de Nou Barris Nord.

La seva història segueix les característiques pròpies d'una entitat d'acció social lligada a una parròquia implicada en la dinamització de la població juvenil del territori. La particularitat de la iniciativa és que, a través del treball professional en la formació $\mathrm{i}$ la inserció sociolaboral de joves, ha anat desenvolupant nous serveis i disposa de projectes que han esdevingut referents per a centres de característiques similars en altres territoris. A través de la canalització de fons privats i el finançament de polítiques públiques vinculades a la dinamització comunitària $i$, sobretot, a l'atenció a la infancia i la joventut en risc d'exclusió social, el Centre Cruïlla ha anat adquirint experiència fins a desenvolupar un projecte complex i agosarat per fer front a la problemàtica concreta (la inserció laboral dels joves) en un territori vulnerable i fortament colpit per la crisi.

El lideratge de la iniciativa el duen a terme professionals del sector social que en molts casos combinen els dos perfils descrits anteriorment amb un alt grau de vinculació emocional i militància activa en la transformació de la realitat local. Gràcies al seu treball en xarxa, l'entitat ha posat en relació els professionals que fan funcionar el Centre Cruïlla amb altres professionals del sector social (educadors socials, mestres d'escola, treballadors de serveis socials) que treballen en el territori, així com amb un reduït grup de veïns que s'impliquen en el funcionament de les entitats cívico-socials d'aquests barris. El Centre Cruilla ha esdevingut amb el temps un referent del desenvolupament comunitari i en l'actualitat gestiona el Pla de Desenvolupament Comunitari 
de Nou Barris Nord, que s'ocupa de fer treballar en comú totes les entitats i organitzacions socials de la zona.

D'altra banda, el Centre Cruïlla destaca com una entitat del tercer sector que té ben identificades les prioritats de les seves activitats i que, en l'àmbit de la inserció sociolaboral de joves, ha esdevingut un referent per a tots els centres d'inspiració salesiana catalans. El model del Centre Cruilla s'ha estès a altres territoris amb centres oberts que duen a terme acció social amb joves. També ha estat pioner, entre els centres oberts de la comunitat salesiana, a experimentar al voltant de la gestió de contractes de treball temporal per als joves que passen pels seus itineraris formatius. Aquests contractes, encara que normalment són molt puntuals i es limiten a hores o a dies, tenen un evident efecte d'apoderament entre la població amb què tenen contacte.

L'impacte de la iniciativa és molt limitat i no es pot dir que sigui altament eficaç si tenim en compte les condicions d'emergència social que pateix el territori on es troba. Per contra, sí que s'ha d'assenyalar que, en aquest cas —en un entorn amb mancances estructurals molt greus i un dèficit històric d'atenció per part de les polítiques públiques des d'una perspectiva integral-, es posa en relleu que poden haver-hi casos de creativitat social en condicions molt extremes. La causa d'això, malgrat la situació de deixadesa institucional del context, potser s'ha de relacionar amb la temàtica en concret amb què tracta l'entitat. El Centre Cruilla ha esdevingut un referent pel seu grau d'especialització en un aspecte concret en què ni les polítiques públiques ni el finançament privat de fundacions i entitats financeres han deixat d'existir del tot. A més, des d'una perspectiva antropològica, cal considerar que l'atenció a la infancia i la joventut probablement és una de les qüestions en què primer es posa de manifest la vinculació solidària i cívica d'una comunitat.

\section{2. $50 \times 20$}

$50 \times 20$ és una iniciativa sorgida en un context històrico-geogràfic determinat per l'absència de polítiques integrals que abordin la lluita contra l'exclusió. Darrere de $50 \times 20$ hi ha un grup d'unes cinquanta persones compromeses amb el teixit associatiu de Nou Barris Nord, disposades a donar periòdicament cada mes $20 €$ per pal-liar la manca de recursos públics i l'oblit endèmic que pateix el territori de Nou Barris Nord en general i el seu teixit associatiu en particular. Es tracta d'una iniciativa, per tant, que ha de ser interpretada com un exemple de resiliència ciutadana que pretén pal.liar una situació d'alta vulnerabilitat, però que, alhora, assenyala mancances en el rol provisor de les administracions públiques pel que fa a les polítiques de benestar.

$50 \times 20$ actua com una caixa de resistència que ofereix diners a les entitats cíviques i, fins i tot, a centres públics com són les escoles del barri per donar resposta a situacions d'emergència social que no troben solució pels canals oficials associats a les polítiques de benestar. En aquest sentit, posa en relleu les dinàmiques de vulnerabilitat i d'estigmatització a què s'enfronta el territori. 
El principal impacte discursiu d'una experiència com $50 \times 20$, que no ha pretès en cap moment fer una tasca comunicativa de conscienciació de l'opinió pública, es dona al marge de la seva orientació pràctica. $50 \times 20$ no busca estar present als diaris, ni tan sols busca la visibilitat com a entitat en el territori on opera o entre les persones que se'n beneficien. Simplement es preocupa d'oferir una eina a les entitats socials i cíviques que treballen al barri promovent processos socioeducatius i pensant específicament a pal-liar les situacions d'impotència amb què es troben mestres, educadors i activistes socials del barri pel que fa a la manca de suport a les necessitats de la població.

La caixa de resistència de $50 \times 20$ serveix per pagar serveis mèdics d'urgència, activitats extraescolars, beques menjador i colònies, petites reparacions en habitatges amb condicions insuficients d'habitabilitat i impagaments pel que fa a subministraments bàsics, entre altres qüestions. De manera complementària, promou processos de transformació socioeducativa entre les persones beneficiàries dels recursos que ofereix, buscant sempre l'establiment de compromisos entre les entitats mediadores en l'ús dels recursos financers i les persones del territori que se'n beneficien directament. En cap moment, però, la iniciativa s'ha plantejat substituir el paper de les administracions, ans al contrari. Els membres que mantenen viva l'organització d'aquesta caixa de resistència es preocupen activament d'exigir responsabilitats a les administracions corresponents.

Si s'analitza el personal que s'ocupa de fer funcionar $50 \times 20$, destaquen entre cinc $\mathrm{i}$ sis persones, a més de la cinquantena de socis que posen diners mensualment en un compte corrent en comú. Aquestes persones generalment tenen una activitat professional estable i estan compromeses amb la lluita per transformar la zona, en molts casos perquè han viscut en la pròpia pell l'estigma social vinculat a Nou Barris Nord.

La voluntat de $50 \times 20$ d'oferir recursos financers establint vincles entre les diferents entitats del territori i subratllant el seu protagonisme en l'acció per a la transformació social denota un grau elevat de capital cultural a l'hora de concebre el lideratge compartit i col-lectiu en les dinàmiques $\mathrm{i}$ els processos de transformació social. L'entitat també actua reformulant el discurs, això vol dir redefinint els termes de la problemàtica sobre la situació d'emergència social que viu el barri. Un exemple molt clar n'és l'èmfasi que des de la iniciativa es posa a atraure un equipament o un servei de ciutat que posi Nou Barris Nord al mapa global de la ciutat com un lloc on es pot desenvolupar una vida digna $\mathrm{i}$ on es disposa de serveis i recursos atractius per a tots els barcelonins.

L'impacte de la iniciativa a l'hora de satisfer les necessitats bàsiques del barri és força limitat, ja que gestiona pocs recursos. Tot i això, $50 \times 20$ incideix en la definició del relat de les problemàtiques del barri i, en conseqüència, en les relacions de poder. Es tracta d'una entitat que indirectament posa l'accent en la manca de compromís i inversió pública, alhora que subratlla que el que necessita aquesta zona són polítiques de tipus estructural que plantegin intervencions integrals i holístiques. 


\section{Síntesi analítica}

Centrant l'anàlisi en quatre iniciatives socialment innovadores en dos territoris diferents de Barcelona, s'ha comprovat que, tant les característiques històrico-geogràfiques dels barris com les pràctiques de lideratge, no només són variables útils per comprendre l'impacte de la innovació social (taula 2) sinó que, a més, són variables que mantenen una relació dialèctica.

\subsection{L'efecte barri i la construcció de capacitats comunitàries}

Hem pogut veure en els nostres estudis de casos que el context històric, geogràfic i social és clau per comprendre la potencialitat transformadora de les iniciatives ciutadanes contra la crisi. Tanmateix, en contra de l'argument que les dinàmiques d'exclusió social són un catalitzador per a la innovació social (Moulaert et al., 2010), s'han trobat força evidències que posen en relleu que

Taula 2. Eficàcia i escalabilitat de les iniciatives

\begin{tabular}{|c|c|c|c|c|}
\hline & \multicolumn{2}{|c|}{ Sants } & \multicolumn{2}{|c|}{ Nou Barris Nord } \\
\hline & Can Batlló & РAH & Centre Cruïlla & $50 \times 20$ \\
\hline \multicolumn{5}{|l|}{ Eficàcia } \\
\hline $\begin{array}{l}\text { Satisfacció } \\
\text { de necessitats } \\
\text { socials }\end{array}$ & $\begin{array}{l}\text { Impacte alt, } \\
\text { sobretot } \\
\text { al barri. }\end{array}$ & $\begin{array}{l}\text { Impacte alt, però } \\
\text { caldrien canvis } \\
\text { estructurals i } \\
\text { institucionals } \\
\text { per solucionar } \\
\text { el problema. }\end{array}$ & $\begin{array}{l}\text { Impacte mitjà, } \\
\text { programa reei- } \\
\text { xit però d'abast } \\
\text { limitat. }\end{array}$ & $\begin{array}{l}\text { Impacte baix, és } \\
\text { una iniciativa amb } \\
\text { pocs recursos. }\end{array}$ \\
\hline Apoderament & $\begin{array}{l}\text { Apoderament } \\
\text { d'activistes. }\end{array}$ & $\begin{array}{l}\text { Apoderament } \\
\text { de les persones } \\
\text { afectades. }\end{array}$ & $\begin{array}{l}\text { Recursos i capa- } \\
\text { citats per als joves } \\
\text { beneficiaris de la } \\
\text { iniciativa. }\end{array}$ & $\begin{array}{l}\text { Recursos per a } \\
\text { les organitzacions } \\
\text { beneficiàries. }\end{array}$ \\
\hline $\begin{array}{l}\text { Canvis en les } \\
\text { relacions socials } \\
\text { i de poder }\end{array}$ & $\begin{array}{l}\text { Sí. La lluita ha } \\
\text { tingut èxit i s'ha } \\
\text { creat una nova } \\
\text { plataforma que } \\
\text { enxarxa diferents } \\
\text { actors. }\end{array}$ & $\begin{array}{l}\text { Sí. La lluita ha } \\
\text { tingut èxit i la PAH } \\
\text { ha esdevingut un } \\
\text { nou actor contes- } \\
\text { tatari. }\end{array}$ & $\begin{array}{l}\text { Parcialment. Nou } \\
\text { espai de relació } \\
\text { amb el Pla de } \\
\text { Desenvolupament } \\
\text { Comunitari. }\end{array}$ & $\begin{array}{l}\text { Parcialment. } \\
\text { La iniciativa rela- } \\
\text { ciona actors del } \\
\text { barri. }\end{array}$ \\
\hline \multicolumn{5}{|l|}{ Escalabilitat } \\
\hline $\begin{array}{l}\text { Arriba a més } \\
\text { gent }\end{array}$ & $\begin{array}{l}\text { Sí. La iniciativa } \\
\text { ha crescut } \\
\text { i ha implicat } \\
\text { més gent. }\end{array}$ & $\begin{array}{l}\text { Sí. La iniciativa } \\
\text { ha crescut i ha } \\
\text { implicat més gent. }\end{array}$ & $\begin{array}{l}\text { Limitadament. } \\
\text { És una iniciativa } \\
\text { petita. }\end{array}$ & $\begin{array}{l}\text { No. És una } \\
\text { iniciativa molt } \\
\text { petita. }\end{array}$ \\
\hline $\begin{array}{l}\text { Supera l'escala } \\
\text { territorial del } \\
\text { barri }\end{array}$ & $\begin{array}{l}\text { Parcialment. } \\
\text { La iniciativa } \\
\text { desperta interès } \\
\text { fora del barri. }\end{array}$ & $\begin{array}{l}\text { Sí. La PAH té } \\
\text { assemblees locals } \\
\text { per tot el país. }\end{array}$ & $\begin{array}{l}\text { Parcialment. La } \\
\text { iniciativa desperta } \\
\text { interès fora del } \\
\text { barri. }\end{array}$ & $\begin{array}{l}\text { No. És una inicia- } \\
\text { tiva estrictament } \\
\text { local. }\end{array}$ \\
\hline
\end{tabular}

Font: elaboració pròpia. 
la innovació social no sorgeix necessàriament en els barris amb més necessitats socials, fet que ja han apuntat recentment Blanco et al. (2016), sinó més aviat en els que tenen més capacitats per impulsar-la.

La substitució demogràfica a Nou Barris Nord ha suposat un debilitament de les capacitats d'acció comunitària d'un territori ja per si mateix vulnerable condicionat per l'endarreriment de la inversió pública. Com a resultat d'aquest procés, el seu teixit social s'ha fragmentat i debilitat. Al mateix temps, l'estigmatització social associada al territori no facilita la consolidació d'un sentiment de pertinença entre els que hi habiten. D'altra banda, es pot identificar també una manca de col-laboració i coordinació, no només entre actors governamentals i no governamentals - on ha predominat una relació d'hostilitat i desconfiança- sinó també entre diferents tipus d'actors governamentals i àrees de la mateixa Administració. En aquest context, $50 \times 20$ actua completament fora dels organismes públics i això explica que el seu impacte tingui limitacions evidents. Bàsicament fa una tasca de contenció que, en cert sentit, mira d'estructurar les relacions de solidaritat i veïnatge dins del mateix barri. Una cosa similar trobem al Centre Cruilla, malgrat que aquesta entitat sí que estableix relacions amb altres actors, tant comunitaris com privats i governamentals. El context d'un barri on les xarxes sociocomunitàries tendeixen a la fragilitat, doncs, incideix a dificultar tant l'eficàcia com l'escalabilitat de les iniciatives de transformació social que s'hi donen.

Sants, per la seva banda, és un barri especialment polititzat amb una història considerable d'activisme social. Allà, s'hi pot trobar una comunitat relativament ben connectada que té una experiència de colllaboració amb les administracions públiques en què les negociacions — el pacte, però també el conflicte - han estat viscudes com processos col-lectius i dinàmics. D'altra banda, diverses iniciatives de Sants vinculen antics i nous activismes. El paper de joves amb un bagatge formatiu considerable i una cultura política vinculada als moviments socials per desenvolupar respostes socialment innovadores a Sants és especialment significant. La innovació social en aquest context beu directament de la tradició col-laborativa del barri i es beneficia de la capacitat per vincular, de forma molt resolutiva, persones a títol individual amb organitzacions ciutadanes. Si s'observen les dues iniciatives analitzades a Sants, es pot afirmar que, tot i les seves limitacions, tenen un grau molt alt d'escalabilitat i d'impacte efectiu.

Cal subratllar que, d'una banda, les condicions de vulnerabilitat socialment produïdes a cada territori condicionen les possibilitats d'emergència i desenvolupament d'iniciatives socialment innovadores. Aquesta observació suggereix una recomanació als poders públics que vulguin facilitar el desenvolupament de dinàmiques d'innovació social transformadores. Més que centrar-se en la replicabilitat d'experiències, és oportú proposar que les polítiques públiques comunitàries s'orientin a construir capacitats — habilitats i recursos- en els territoris més desafavorits. 


\subsection{Pràctiques de lideratge per a una agència col.lectiva}

Més enllà del context territorial en què es desenvolupen les diferents iniciatives estudiades, s'ha pogut observar com l'ús diferencial de determinades pràctiques de lideratge (taula 3) és útil per entendre la major o menor capacitat d'impacte d'aquestes iniciatives. L'agència, doncs, també té un paper important, fet que permet explicar, per exemple, que en geografies adverses per a la innovació social, com Nou Barris Nord, hi sorgeixin iniciatives més o menys reeixides com les que hem analitzat. Això es pot veure més concretament a través de les tres pràctiques de lideratge observades.

Reformular el discurs. La reformulació del discurs és probablement la pràctica de lideratge que té el major impacte, tant en termes d'eficàcia com d'escalabilitat. Produir nous marcs analítics i discursius pot ser una forma tant d'apoderament ciutadà, en el sentit que serveix per trencar estereotips incrustats en els discursos dominants, com de visualització de noves solucions.

Recuperem Can Batlló promou una crítica general a la manera com la ciutat ha estat construïda i transformada, i proposa una comprensió radical i disruptiva d'allò que és "públic» des d'una aproximació emancipadora. La PAH desafia la descripció de la crisi hipotecària promoguda per les autoritats públiques i els agents econòmics hegemònics $i$ ha desenvolupat un relat alternatiu que ha aconseguit transformar la percepció social sobre la crisi d'una gran majoria social (Flesher Fominaya, 2015). A través de la reformulació del discurs, aquestes iniciatives han generat relats contrahegemònics que els han permès arribar a més gent (scaling out) i superar l'escala territorial del barri (scaling up). Al mateix temps, la producció de nous discursos (i noves solucions) ha qüestionat el marc preestablert i ha incidit també en les relacions de poder preexistents.

Taula 3. Pràctiques de lideratge en les iniciatives

\begin{tabular}{|c|c|c|c|c|}
\hline & \multicolumn{2}{|c|}{ Sants } & \multicolumn{2}{|c|}{ Nou Barris Nord } \\
\hline & Can Batlló & $\mathrm{PAH}$ & Centre Cruïlla & $50 \times 20$ \\
\hline $\begin{array}{l}\text { Reformular } \\
\text { el discurs }\end{array}$ & $\begin{array}{l}\text { Nova concep- } \\
\text { ció del que és } \\
\text { públic des d'una } \\
\text { perspectiva } \\
\text { comunitària i } \\
\text { emancipadora. }\end{array}$ & $\begin{array}{l}\text { Nou relat de les } \\
\text { causes i responsa- } \\
\text { bilitats de la crisi. } \\
\text { L'habitatge com } \\
\text { un dret. }\end{array}$ & $\begin{array}{l}\text { Nova aproxima- } \\
\text { ció a la inserció } \\
\text { sociolaboral i al } \\
\text { desenvolupament } \\
\text { sociocomunitari. }\end{array}$ & $\begin{array}{l}\text { La iniciativa recla- } \\
\text { ma inversió integral } \\
\text { i ressalta el paper } \\
\text { del teixit associa- } \\
\text { tiu, assistencial i } \\
\text { educatiu. }\end{array}$ \\
\hline $\begin{array}{l}\text { Construir ponts } \\
\text { entre diferents }\end{array}$ & $\begin{array}{l}\text { Xarxa de diferents } \\
\text { organitzacions i } \\
\text { individus. }\end{array}$ & $\begin{array}{l}\text { Ponts entre dife- } \\
\text { rents classes: } \\
\text { activistes i afec- } \\
\text { tats. }\end{array}$ & $\begin{array}{l}\text { Ponts entre els } \\
\text { actors de la } \\
\text { comunitat. }\end{array}$ & $\begin{array}{l}\text { Xarxa entre orga- } \\
\text { nitzacions del barri. }\end{array}$ \\
\hline $\begin{array}{l}\text { Alliberar } \\
\text { energies } \\
\text { humanes }\end{array}$ & $\begin{array}{l}\text { A través de } \\
\text { l'autoorganització. }\end{array}$ & $\begin{array}{l}\text { Apoderant i capa- } \\
\text { citant les persones } \\
\text { afectades. }\end{array}$ & $\begin{array}{l}\text { Formant i capaci- } \\
\text { tant joves. }\end{array}$ & $\begin{array}{l}\text { A través de l'au- } \\
\text { toorganització i el } \\
\text { suport mutu. }\end{array}$ \\
\hline
\end{tabular}

Font: elaboració pròpia. 
Més pragmàtica és la reformulació de les iniciatives estudiades a Nou Barris Nord, fet que limita també la seva capacitat d'impacte en termes de transformació de les relacions de poder. El Centre Cruilla promou un nou marc conceptual sobre la inclusió sociolaboral dels joves movent-se d'una aproximació simplement educacional i assistencialista cap a una aproximació més integral. $50 \times 20$ posa de manifest que les institucions públiques no protegeixen les persones d'aquests barris i argumenta la necessitat d'una major inversió pública que desenvolupi un projecte de transformació des d'una perspectiva integral, superant la perspectiva d'intervencions sectorials aillades.

Construir ponts entre diferents actors. Incrementar la diversitat d'agents implicats en la transformació social, incloent-hi diferents grups i actors, ajuda a produir millors diagnòstics i millors solucions als problemes socials. Alhora, l'establiment d'aliances entre actors de diferent tipus pot ajudar a engrandir l'abast d'una iniciativa en promoure la inclusió de nous usuaris en les seves activitats. Quan aquestes aliances, a més, incorporen actors de diferents escales, es facilita enormement l'escalabilitat de la iniciativa.

La plataforma Recuperem Can Batlló procura vincular actors tradicionals d'entitats civicosocials del teixit associatiu del barri amb representants dels moviments socials i persones a títol individual, i atorga també importància a la hibridació de formes organitzacionals per part dels seus diferents projectes. $\mathrm{La} \mathrm{PAH}$ practica la interlocució amb les administracions públiques i treballa en col-laboració amb aquestes, alhora que promou la col-laboració entre afectats i activistes pel dret a l'habitatge. El Centre Cruilla treballa en un marc multiescalar buscant el suport de tot tipus de fonts de finançament, siguin públiques o privades. De fet, aquesta capacitat de treball en xarxa és el que pot explicar l'impacte de la iniciativa en un context advers. En el cas de $50 \times 20$, a escala molt local l'entitat té un paper d'intermediari entre les associacions del barri en apoderar-les com a agents de canvi social i, alhora, posant de manifest davant de les administracions públiques la insuficiència i la indefensió del teixit associatiu, assistencial i educatiu del territori per fer front a les problemàtiques socioeconòmiques amb què s'enfronta.

Alliberament d'energies humanes. Finalment, en tots els casos analitzats trobem grups socials específics amb recursos limitats que s'estan apoderant a través d'una atenció específica a la millora de la capacitació personal dels individus.

La PAH dona una importància cabdal a la superació personal de la culpabilització per part de les víctimes de l'especulació immobiliària, al mateix temps que desenvolupa múltiples accions de capacitació dels seus membres. El Centre Cruilla es preocupa d'oferir experiències d'autonomia laboral a joves amb una inserció en el mercat de treball difícil. $50 \times 20$ atorga importància a evitar l'assistencialisme requerint contrapartides socioeducatives en forma de compromisos per part de les persones que es beneficien del seu suport. Finalment, la plataforma Recuperem Can Batlló s'inspira en l'objectiu d'alliberar espais per a l'autoorganització comunitària de la vida quotidiana; és a dir, promou l'apoderament de les persones implicades a través de la seva autoorganització. 
A través d'aquestes tres pràctiques de lideratge, les iniciatives socialment innovadores activen una capacitat d'agència col-lectiva que contribueix a satisfer millor les necessitats bàsiques a les quals es pretén fer front, a facilitar l'apoderament cívic a les persones implicades i a transformar les relacions de poder.

\subsection{Conclusió: la dialèctica entre context $i$ agència}

Els casos presentats mostren que el context històrico-geogràfic i l'agència col-lectiva de les iniciatives socialment innovadores no són dues dimensions d'anàlisi ailllades i inconnexes sinó que es relacionen de forma dialèctica. D'una banda, el context històrico-geogràfic condiciona les possibilitats d'implementació d'algunes de les pràctiques de lideratge. Així, un context més vulnerable i socialment més fragmentat com Nou Barris Nord és més propici a una reformulació del discurs amb una orientació més pragmàtica i fa més difícil que se salvin les diferències entre grups. En canvi, en un barri on les condicions d'habitabilitat no són tan dures i el teixit social és més cohesionat i polititzat, la reformulació del discurs tendeix a ser més transformadora i la construcció de ponts és més facil. Tanmateix, un dels casos en què les tres pràctiques de lideratge tenen un impacte més elevat, el de la PAH, és el cas en què el vincle territorial apareix com a menys important; fet que reforça la idea que, més enllà del context territorial, les pràctiques de lideratge són importants en si mateixes.

D'altra banda, s'ha observat que les pràctiques de lideratge contribueixen no només a l'eficàcia i l'escalabilitat de les pròpies iniciatives, sinó també a transformar les característiques i les capacitats comunitàries del barri. Contribueixen, doncs, a transformar el context. Això es pot veure en casos com el Centre Cruilla, on la seva habilitat per construir ponts entre diferents actors està canviant les relacions del conjunt del barri. El context històrico-geogràfic, doncs, és dinàmic i pot ser transformat tant a través de les pràctiques de lideratge de les iniciatives socialment innovadores com també mitjançant polítiques públiques que fomentin la construcció de capacitats comunitàries.

\section{Referències bibliogràfiques}

Blanco, Ismael; Cruz Gallach, Helena; Martínez Moreno, Rubén i Parés, Marc (2016). "El papel de la innovación social frente a la crisis». Ciudad y Territorio. Estudios Territoriales, XLVIII (188), 249-260.

BlAnCO, Ismael i GOMÀ, Ricard (2016). El municipalisme del bé comú. Barcelona: Icaria.

Eizaguirre, Santiago; Pradel, Marc; Terrones, Albert; Martinez-Celorrio, Xavier i GARCíA, Marisol (2012). «Multilevel Governance and Social Cohesion: Bringing Back Conflict in Citizenship Practices». Urban Studies, 49 (9), 1999-2016. <https://doi.org/10.1177/0042098012444890>

Flesher Fominaya, Cristina (2015). «Redefining the Crisis/Redefining Democracy: Mobilising for the Right to Housing in Spain's PAH Movement». South European Society and Politics, 20 (4), 465-485. <https://doi.org/10.1080/13608746.2015.1058216> 
Heifetz, Ronald A.; Grashow, Alexander i Linsky, Marty (2009). The Practice of Adaptive Leadership: Tools and Tactics for Changing Your Organization and the World. Cambridge: Harvard Business Press.

LACOL (2014). Inventari de Can Batlló. Teixint una història col-lectiva. Barcelona.

MacCallum, Diana; Moulaert, Frank; Hillier, Jean i Vicari Haddock, Serena (2009). Social Innovation and Territorial Development. Farnham: Ashgate.

Mir Garcia, Jordi; França, João; Macias, Carlos i Veciana, Paula (2013). «Fonaments de la Plataforma d'Afectats per la Hipoteca: activisme, assessorament col.lectiu i desobediència civil no violenta». Educacio Social. Revista d'Intervenció Socioeducativa, 55, 51-60.

Moulaert, Frank; MacCallum, Diana; Mehmood, Abid i Hamdouch, Abdelillah (2013). The International Handbook on Social Innovation. Cheltenham: Edward Elgar. <https://doi.org/10.4337/9781849809993>

Moulaert, Frank; Martinelli, Flavia; Swyngedouw, Erik i GonZÁlez, Sara (2010). Can Neighbourhoods Save the City? Nova York: Routledge.

OjedA, Helena i URBAnO, Xavier (2015). «Cultura i gestió comunitària. Públic significa 'de la comunitat', no 'del Govern'». Espaifabrica.cat.

Oosterlynck, Stijn; Kazepov, Yuri; Wukovitsch, Florian; Sarius, Tatiana i LeuBOLT, Bernhard (2013). "The Butterfly and the Elephant : Local Social Innovation, the Welfare State and New Poverty Dynamics». Ideas 13/03.

OspinA, Sonia (2006). "Gobernanza y liderazgos para el cambio social». Revista del CLAD. Reforma y Democracia, 35, 93-122.

OspinA, Sonia i El Hadidy, Waad (2013). «How Social Change Organizations Create Leadership Capital and Realize Abundance amidst Scarcity». Nova York: Research Center or Leadership in Action.

Ospina, Sonia; Foldy, Erica Gabrielle; El Hadidy, Waad; Dodge, Jeniffer; Hofmann-Pinilla, Amparo i Su, Celina (2012). "Social Change Leadership as Relational Leadership». A: Mary UHL-BIEn i Sonia M. OspinA (eds.). Advancing Relational Leadership Research. A Dialogue Among Perspectives. Charlotte, NC: Information Age, 255-302.

PalOmera, Jaime (2014). «How did Finance Capital Infiltrate the World of the Urban Poor? Homeownership and Social Fragmentation in a Spanish Neighborhood». International Journal of Urban and Regional Research, 38 (1), 218-235. <https://doi.org/10.1111/1468-2427.12055>

Parés, Marc; Bonet-Martí, Jordi i MArTí-Costa, Marc (2012). «Does Participation Really Matter in Urban Regeneration Policies? Exploring Governance Networks in Catalonia (Spain)». Urban Affairs Review, 48 (2), 238-271. <https://doi.org/10.1177/1078087411423352>

PARÉS, Marc; OsPINA, Sonia i SuBIRATS, Joan (2017). Social Innovation and Democratic Leadership. Communities and Social Change from Below. Cheltenham: Edward Elgar.

Pradel, Marc; Eizaguirre, Santiago i García, Marisol (2013). "Theorising Multi-Level Governance in Social Innovation Dynamics». A: Frank Moulaert, Diana MacCallum, Abid Mehmood i Abdelillah Hamdouch (eds.). The International Handbook on Social Innovation. Collective Action, Social Learning and Transdisciplinary Research. Cheltenham: Edward Elgar, 155-168.

Romanos, Eduardo (2014). «Evictions, Petitions and Escraches: Contentious Housing in Austerity Spain». Social Movement Studies: Journal of Social, Cultural and Political Protest, 13 (2), 296-302. <https://doi.org/10.1080/14742837.2013.830567> 
Subirats, Joan i GarCíA-BERnADOs, Ángela (2015). Innovacion social y politicas urbanas en España. Experiencias significativas en las grandes ciudades. Barcelona: Icaria.

Subirats, Joan i Martí-Costa, Marc (2014). Ciudades, vulnerabilidades y crisis en España. Sevilla: Centro de Estudios Andaluces.

- (2015). Ciudades y cambio de época: discursos sobre politicas urbanas y crisis en España. Bilbao: Universidad del País Vasco.

Uhl-Bien, Mary i Ospina, Sonia (2012). Advancing Relational Leadership Theory: A Conversation among Perspectives. Charlotte, NC: Information Age.

YIN, Robert (2003). Case Study Research. Design and Methods. Londres: SAGE. 